\title{
Bureaucrats under Populism
}

\author{
Greg Sasso* $\quad$ Massimo Morelli ${ }^{\dagger}$
}

August 9, 2021

\begin{abstract}
We explore the consequences of populism for bureaucrats' incentives by analyzing a model of delegated policymaking between politicians and bureaucrats. Populist politicians prefer a bureaucrat who implements their policy commitment, while non-populist politicians prefer a good bureaucrat with discretion. The presence of populist politicians thus determines replacement of good with bad bureaucrats and creates incentives for good bureaucrats to "feign loyalty". We show that feigning loyalty is more prevalent when the probability of populist leadership in the future is higher and the bureaucrats' pool of potential replacements is worse. We also show that bureaucratic turnover is higher under populists when the bureaucracy is strong and higher under non-populists when the bureaucracy is weak.
\end{abstract}

JEL Codes: C72, D72, D73, D78

Keywords: Populism, Bureaucracy, Principal-Agent

*Emory University, Email: gregory.sasso@emory.edu. Corresponding Author

${ }^{\dagger}$ Bocconi University, IGIER, PERICLES and CEPR. Email: massimo.morelli@ unibocconi.it. 


\section{Introduction}

Populists' rhetoric often includes criticism of the bureaucracy. ${ }^{1}$ However, policymaking is a complex process and policy implementation requires use of the bureaucracy. Even when populists are in power, high-level agents are needed for implementation and can greatly affect policy. To combat this, populist leaders often try to hire their own loyalist agents (Müller 2017). ${ }^{2}$ The Trump administration had a far higher number of overturned policies than previous administrations (Barbash and Paul 2019). Moreover, the higher rate of turnover among appointees (Tenpass 2018) is likely to have instability effects, incentive distortion effects, and to reduce institutional memory.

In this paper we characterize the equilibrium incentives of populist and non-populist politicians in terms of the choice of bureaucrats, whose competence (good or bad) is private information. We assume that a populist politician prefers the bureaucrat policymaker to implement a fixed policy whereas a non-populist politician typically prefers delegation to good bureaucrats who are able to match the policy to the changing states of the world. ${ }^{3}$ This difference implies that a populist may prefer a bad bureaucrat over a good bureaucrat. In fact, for a bad bureaucrat the opportunity cost of loyalty to the populist fixed policy is lower than for a good bureaucrat, since the latter knows what the correct policy would be and the bad does not. Beside analyzing the different hiring and firing

\footnotetext{
${ }^{1}$ Peters and Pierre (2019) emphasize this to the point of including this feature in the definition of populists itself: "political leaders and movements that emphasize the venality of political leaders (including the bureaucracy) and press for greater power for the people." The most widely used definition of populism by Mudde (2004), emphasizing the contrast between "the pure people" versus "the corrupt elite", did not explicitly contain the bureaucracy or any other element of the list of targets included in the elite, but the frequent observations justify the direct inclusion in Peters and Pierre's definition.

${ }^{2}$ As an example, consider the case of President Trump's Director of National Intelligence. In February 2020, Trump fired the acting director, Joseph Maguire, and installed a new acting director, Richard Grenell. Trump preferred Grenell even though Grenell had no prior intelligence experience and Maguire was a respected former Admiral. When talking about the hiring of Grenell, the former head of the National Counterterrorism Center stated that "personal loyalty is prized above relevant experience and demonstrated competence" (Barnes and Haberman 2020).

${ }^{3}$ Morelli, Nicoló and Roberti (2021) derive the policy commitment strategy of populists from first principles. Given the significant drop in trust by voters documented by many scholars due to globalization and the great recession, it is rational for politicians to enter with a committed delegate strategy, in contrast with the traditional trustee model of representative democracy. See also Fox and Shotts (2009) and Fox and Jordan (2011) for other models where the committed delegate model can be chosen because a trustee would reduce accountability. What Morelli, Nicoló and Roberti (2021) add is the demonstration that the typical policies associated to populism (i.e. anti-elite rhetoric, fake news production, anti-media and anti-expert rhetoric) are strategic complements to having chosen the committed delegate model of political agency.
} 
decisions by politicians, we also characterize the consequent incentive distortions by good and bad bureaucrats.

We study the problem with a two period game where in each period there are just two players, namely a politician and a bureaucrat. The politician can be populist or not, and the bureaucrat can be good or bad. In each period, the incumbent politician decides on whether to fire the incumbent bureaucrat; if the bureaucrat is fired a new one is randomly chosen. The bureaucrat in office then chooses a policy. In between the first and second period there is an election, and a new politician type may take office for the second period.

Morelli, Nicoló and Roberti (2021) provide a micro-foundation of the choice of unconditional platforms for a politician, and also show why the choice of a commitment strategy leads to all the other features of populism as well. They show that when delegation is plagued by risk of capture by interest groups or elites and hence trust in politicians is low, parties and politicians may find it rational to make policy commitments, like building walls, protectionism, nationalism. The model presented here shows the consequences the strategic choice of populist commitments has for bureaucratic appointments, policy implementation and bureaucratic behavior. Populists want loyal bureaucrats who do not challenge their policy commitment they made with voters - a political agency motivation for not wanting resistance by (or delegation to) the bureaucracy. Thus, a populist politician wants to fire experts in order to reduce potential resistance or to avoid that the bureaucracy can end up implementing a different policy.

Good bureaucrats know the state of the world while the bad ones have no extra information in the model. Besides this difference, both bureaucratic types are exactly the same. They care about office rents and also about correctly matching policy to the state of the world. However, only good bureaucrats can successfully implement the correct policy; the best bad bureaucrats can do is match public interest in expectation. By conditioning office rents on implementation of the populist policy, populist politicians can entice bureaucrats away from pursuing the correct policy. Crucially, the necessary rents are lower for bad than for good bureaucrats. Bad bureaucrats can only match policy with the state in expectation, and this gives them a lower expected policy payoff than good 
bureaucrats. Therefore bad bureaucrats optimally choose to act as loyalists in a much larger set of circumstances. Good bureaucrats sometimes choose the populist policy as well, because this type of pooling behavior avoids firing and hence may be preferred when office rents are very high and/or the optimal policy is not far from the populist desired policy. The different frequencies of endogenous loyal behavior ensures that populist politicians have a strict preference for bad bureaucrats.

Bureaucrats may decide to compromise on policy today to make sure they are around to handcuff populists in the future. The bureaucrat would have to act loyal in order to fool the politicians. We refer to this outcome as feigning loyalty. She intentionally ignores her information about the state of the world today in order to be in position to possibly stop bad populist policies tomorrow. ${ }^{4}$ On the other hand, the bureaucrat can act sincerely today, regardless of future consequences, and choose to implement the correct policy. ${ }^{5}$ The threat of a populist politician partnered with a bad bureaucrat in the future may drive the good bureaucrat's behavior today. This has important implications for thinking about bureaucratic behavior and the consequences of populism.

Perhaps counter-intuitively, we also find that a strong bureaucracy (in the sense of a high proportion of good bureaucrats in the pool from which one is hired) coupled with a high likelihood of a non-populist in the second period can induce feigning loyalty in first period. The expert knows she will be fired if she acts sincerely in the first period. In addition, she knows she is guaranteed second period office rents if she is retained today and a non-populist takes over in the second period. Therefore she has a large incentive to compromise today, and try to stick-it-out through the populist's tenure. This distortion is larger when populists are expected to be voted out of office. The stick-it-out effect encourages feigning loyalty when it is better from a social welfare perspective to act sincerely. This result highlights how even short term populism can have severe distortionary effects.

We also look at how bureaucratic turnover is affected by populism. When good bureaucrats act sincerely, politicians can always tell the type of the bureaucrat. When they feign loyalty, however, politicians learn nothing. We find that as the bureaucracy becomes weaker, turnover is more likely

\footnotetext{
${ }^{4}$ This mechanism is similar to Morris (2001) where a sender may withhold truthful information from a receiver in order to appear unbiased. Also see Lee (2020) for a model where politicians feign being a good type.

${ }^{5}$ There is anecdotal evidence of sincere policymaking in the Trump administration. While we call this sincere policymaking, politicians in power often refer to it as sabotage (Heer 2019).
} 
under non-populists than under populists. Similarly, strong bureaucracies result in more turnover under populists than under non-populists.

We study an extension on civil service protections where politicians are only successful in firing a bureaucrat some of the time. Our main results hold, but we also show that civil service protections can have both positive and negative consequences. Strong civil service protections lesson the need for good bureaucrats to feign loyalty to populists so they do with lower probability. However, bad bureaucrats are harder for non-populists to fire, and therefore bad bureaucrats retained by populists in the first period may remain in the second period even if in such a period the politician in office is non-populist. In addition, we also show that strong civil service protections can now induce good bureaucrats to feign loyalty even under non-populists. Because choosing the populist policy may not result in firing, a good bureaucrat can stay in office to protect against a future populist even when the current incumbent is a non-populist.

We then study two other extensions: one where the bureaucrat can be rehired in the second period and one where the good bureaucrat cares more than the bad bureaucrat about policy. We find that these modifications depress the incentive to feign loyalty, but never eliminate it.

\section{Relation with the literature}

Our result on populists preferring bad bureaucrats is related to the competence-loyalty trade-off analyzed in models of autocratic politics. The key difference is that in papers such as Egorov and Sonin (2011) and Zakharov (2016), dictators want non-expert but loyal agents because that's better for regime survival even at the cost of worse policy. On the other hand, in our model non-experts are actually better policy-wise for a populist.

Our paper is in the long tradition of modeling the politician-bureaucratic relationship as a principal-agent problem. As in the seminal contributions of McCubbins, Noll and Weingast (1987, $1989)$ and Epstein and O'Halloran $(1994,1999)$, we model the adverse selection problem facing the politician. Our spatial model of policymaking is also similar to Huber and Shipan (2002). The nonpopulist desire for a expert bureaucrat is similar to the politician's desire for bureaucratic expertise in 
Gailmard and Patty (2007). However, most of the literature assumes the principal remains constant throughout the entire game. In contrast, we show how differences in present and possible future politicians affects bureaucratic behavior today. ${ }^{6}$ See Gailmard and Patty (2012) for a larger survey on the politician-bureaucrat relationship.

While we take the strength or capacity of a bureaucracy as given, Ting (2009) and Gratton et al. (2021) analyze how bureaucratic strength and capacity evolve. We assume that a bureaucrat's expertise is exogenously given. Gailmard and Patty (2007), Callander (2008) and Ting (2009), among others, look at the question of how bureaucrats and bureaucracies develop expertise and capacity.

Our paper also complements Cameron and de Figueiredo (2020), which analyzes why some bureaucrats quit the bureaucracy altogether. They also find stick-it-out effects (denoted "Wait Them Out" and "I Can Make a Difference" in their terminology), where bureaucrats may stay in office in hopes of a more aligned president in the future. However, because bureaucrats do not care about policy after exiting government service in their model, there is no incentive to avoid a bad bureaucrat in the future. This effect partly drives our feigning loyalty result, and is absent from their model.

A few papers try to connect bureaucratic accountability to political accountability (Fox and Jordan 2011; Ujhelyi 2014; Yazaki 2018; Vlaicu and Whalley 2016; Li 2021). In general, these papers show how the presence of a bureaucrat affects the voter's adverse selection problem. We take a reduced form approach to the voter and do not model their behavior explicitly. Our focus is on the politician-bureaucrat relationship, but the model recognizes the politician faces political constraints and incentives.

The concept of feigning loyalty is related to the literature on pandering politicians (Maskin and Tirole 2004; Morelli and Van Weelden 2013; Ashworth and Shotts 2010). In these models, bad types of politicians pander in order to be seen as good type and be reelected. In our model, the good type of bureaucrat pander to be seen as loyal in order to remain in office.

While this paper focuses on the consequences of populism for the administrative state, other

\footnotetext{
${ }^{6}$ Sasso (2020) explores a similar dynamic when future politicians differ in partisan preferences, not populist tendencies.
} 
papers focus on how the populist can bias electoral institutions in his favor and the resulting institutional decay (Luo and Przeworski 2020; Chesterley and Roberti 2018; Funke, Schularick and Trebesch 2021). Our comparative statics speak to the consequences of electoral institutional bias. In a reduced form, increasing the probability of a second period populist would increasing feigning loyalty when bureaucratic strength is low and decrease feigning loyalty when bureaucratic strength is high.

The populist ideal point in our model corresponds to the policy that the populist politician committed to during the electoral campaign, which might well be the policy ex ante preferred by voters as in Morelli, Nicoló and Roberti (2021), or else a policy chosen in order to signal distance from the elite, as in Acemoglu, Egorov and Sonin (2013). But our results apply no matter what the populist ideal point is. Thus, it could in principle be chosen also on the basis of ideology. ${ }^{7}$

\section{Model}

We analyze a two-period model. In each period there are two players: One bureaucrat, denoted $B_{i}, i \in\{g, b\}$ (good and bad respectively) and one politician, denoted $P_{k}, k \in\{p, n\}$ (populist and non-populist).

At the beginning of each period, $t=1,2$, a state of the world $\omega^{t} \in[0,1]$ is realized. The interval $[0,1]$ is the set of feasible policies, hence the realization of the state of the world is simply the realization of what is the optimal policy in that period. Before policymaking, $\omega^{t}$ is observable only to good bureaucrats, whereas bad bureaucrats maintain the prior distribution.

The politician can fire or retain the bureaucrat both before and after policymaking. If she fires the bureaucrat, a new bureaucrat is randomly chosen. The bureaucrat is good with probability $\gamma$ and bad with probability $(1-\gamma)$. The bureaucrat in office at the policymaking stage implements policy $x^{t} \in[0,1]$.

Every period there is a random draw of the politician in office, a populist one with probability $\pi$ and a non-populist with probability $(1-\pi)$. The timing is summarized below:

\footnotetext{
${ }^{7}$ For related models of ideologues, see De Mesquita and Friedenberg (2011) and Ghosh and Tripathi (2012).
} 


\section{Period 1}

(a) Nature draws $\omega^{1}$ and the types of the period 1 bureaucrat and politician.

(b) The politician fires or retains the bureaucrat. If the bureaucrat is fired, Nature draws a new bureaucrat.

(c) If the bureaucrat is good, she observes $\omega^{1}$.

(d) The bureaucrat chooses the policy.

(e) $\omega^{1}$ is observed by all.

(f) The incumbent politician fires or retains the bureaucrat.

(g) Election

\section{Period 2}

(a) Nature draws $\omega^{2}$, the type of the period 2 politician, and the type of the period 2 bureaucrats if necessary.

(b) The politician fires or retains the bureaucrat. If the bureaucrat is fired, Nature draws a new bureaucrat.

(c) If the bureaucrat is good, she observes $\omega^{2}$.

(d) The bureaucrat chooses the policy.

(e) $\omega^{2}$ is observed by all.

(f) The incumbent politician fires or retains the bureaucrat

Payoffs Bureaucrats care about office rents and about policy. Populist politicians want a specific policy regardless of the state of the world; non-populists want policy to match the state of the world. That is, populist politicians have state-independent preferences while non-populists and bureaucrats have state-dependent preferences. ${ }^{8}$

\footnotetext{
${ }^{8}$ The populist fixed desired policy could be e.g. a policy promise made during the electoral campaign. The precise conditions under which one could expect a party to choose a populist vs non populist candidate for an election are given in Morelli, Nicoló and Roberti (2021).
} 
For any player $j$, we denote their ideal policy as $\hat{x}_{j}$. For $j \in\left\{B_{g}, B_{b}, P_{p}, P_{n}\right\}$, each player's per period policy utility is quadratic loss.

A populist politician has as ideal point $\hat{x}_{p}=q \in[1 / 2,1]$. Hence her policy utility is

$$
U_{P_{p}}^{t}\left(x^{t}\right)=-\left(x^{t}-q\right)^{2}
$$

Non-populist politicians want policy to match $\omega$

$$
U_{P_{n}}^{t}\left(x^{t}\right)=-\left(x^{t}-\omega^{t}\right)^{2}
$$

Bureaucrats want policy to match $\omega$ and obtain a payoff of $R$ when in office. Their total per period utility is

$$
U_{B_{g}}^{t}=U_{B_{b}}^{t}=-\left(x^{t}-\omega^{t}\right)^{2}+I^{t} \cdot R
$$

where $I^{t}=1$ if the bureaucrat is in office at the end of period $t$.

The total utility is the (undiscounted) sum of the per-period utilities.

Information At the beginning of the game or after a firing, a bureaucrat is good with probability $\gamma$. At the beginning of each period, the politician is populist with probability $\pi$ and non-populist with complementary probability. Bureaucrat types are private information, but everyone knows the type of the politician in power. $\omega^{1}$ and $\omega^{2}$ are drawn from independent standard uniform distributions. Distributions and probabilities are known to all players.

All players observe $\omega^{1}$ before the next period; this allows politicians to make retention decisions based on the policy and realized state of the world.

Equilibrium and Beliefs This is a dynamic game of incomplete information. The natural equilibrium concept to use is Perfect Bayesian Equilibrium. Off the equilibrium path, we must specify the politicians' beliefs. Let a populist politician believe that if $x^{t}$ is neither equal to $q$ nor $\frac{1}{2}$ then the bureaucrat is good with probability 1 . Let non-populist politicians believe that if $x^{t} \neq \omega^{t}$, then the bureaucrat is good with probability 0 . These two assignments of off-equilibrium beliefs are in 
the spirit of the intuitive criterion: a populist in office knows that deviating from $q$ or $\frac{1}{2}$ must give strictly less utility to a bad bureaucrat, and, similarly, a non populist in office knows that a deviation from an equilibrium where good bureaucrats are sincere must come from a bad bureaucrat. When we talk about "equilibrium" throughout the paper, we always mean PBE with the above assignments of off-equilibrium beliefs.

\section{Discussion}

A few comments on the modeling choices. First, we assume that the politician can fire the bureaucrat before or after policymaking. This seems like the most realistic assumption, as politicians both fire employees that do not follow their directions and also hire new agents when winning office (obviously firing-before is never used in equilibrium in period 1). Firing should not be taken literally. Even in systems where direct political firings are difficult, political interference can still make jobs untenable for bureaucrats. For example, Lt. Colonel Vindman retired from national security duties due to a " 'campaign of bullying, intimidation, and retaliation' spearheaded by the President" (Sciutto 2020). In addition, many bureaucrats find working for the other side untenable and quit even with civil service protections (Bolton, De Figueiredo and Lewis 2021). Firing and hiring of public managers in Italian municipalities happens mostly right after the election of a mayor, as shown in Bellodi, Morelli and Vannoni (2021).

Second, we assume that the bureaucrat has no affect on the likelihood of a populist in the future. This is mostly for expositional and technical clarity. This allows us to really focus on the consequences of populism as opposed to its causes. With the exogenous electoral probability assumption, we follow classic papers such as Dixit, Grossman and Gul (2000) and de Figueiredo Jr (2002). In Morelli, Nicoló and Roberti (2021) the main focus of the analysis is on the parameters and situations where in a two-party competition one chooses a populist commitment strategy and the opponent does not, and both have a positive probability of winning. Hence one can think of our exogenous electoral probabilities as taking their results as given, and then analyzing the consequences of such a framework for the strategic appointments by whoever wins. Levy, Razin and Young (2019) 
also find a positive probability of populists and non-populists in every election as groups of less sophisticated voters may turnout in greater numbers for politicians who promote simplistic policies.

Third, the assumption that both types of bureaucrat are exactly the same outside of their different expertise levels allows us to focus purely on the effects of expertise. However, Gailmard and Patty (2007) show that agents who care more about policy (referred to as zealots in their model) are more likely to develop expertise. Experts are therefore more likely to care more about policy than non-experts. In an extension, we analyze a model where experts care more than non-experts about policy. The results are qualitatively similar to the baseline model.

Fourth, we assume that the state of the world for period 1 is always observed before the second period politician makes his retention decision. This means that the bad bureaucrat cannot fake being expert, as her policy will be incorrect with probability one. If there was some probability that the state of the world was not observed until the end of the game, for example, the bad bureaucrat may be able to appear as an expert. See Gratton et al. (2021) for analysis of such a model.

\section{Analysis}

\subsection{Second Period}

First, we analyze second period behavior. A bad bureaucrat cannot match policy to the state of the world with strictly positive probability even if she wanted. The only information she has is her prior, hence the uniform distribution assumption implies that the best a bad bureaucrat could do in terms of policy utility would be to choose $x^{2}=\frac{1}{2}$. The good bureaucrat knows $\omega^{2}$, and can therefore always match policy to the state.

We assume that a non-populist (resp. populist) politician at end of second period retains only bureaucrats about which the updated probability of being good is greater (resp. smaller) than the prior. $^{9}$ A fired bureaucrat does not receive the office benefit $R$. If a populist is in power, then a good bureaucrat will choose the populist policy if the office benefit plus the expected policy payoff from

\footnotetext{
${ }^{9}$ This assumption would correspond to equilibrium behavior if we wanted to add continuation equilibrium values for the future. Given that the game has only two periods we make this assumption about the end of period 2 behavior for simplicity and for consistency with period 1 behavior.
} 
the populist policy is greater than the expected policy payoff from the optimal policy. We then have the following lemma: ${ }^{10}$

Lemma 1. There exists an equilibrium of the second period policymaking game with the following properties:

1. If in period 2 the politician is $P_{p}$, then

(a) bad bureaucrats implement $x^{2}=q$ (loyalty) if $R \geq\left(q-\frac{1}{2}\right)^{2}$, and $x^{2}=\frac{1}{2}$ otherwise;

(b) good bureaucrats implement $x^{2}=q$ if $\omega^{2} \in[\max \{q-\sqrt{R}, 0\}, \min \{q+\sqrt{R}, 1\}]$ and $x^{2}=$ $\omega^{2}$ otherwise.

2. If $P_{n}$, then

(a) bad bureaucrats implement $x^{2}=\frac{1}{2}$ and

(b) good bureaucrats implement $x^{2}=\omega^{2}$.

3. Populists retain bureaucrats if they implement $x^{2}=q$ and fire all others.

4. Non-populists retain bureaucrats if they implement $x^{2}=\omega^{2}$ and fire all others.

An office rent $R>\bar{R}:=\left(q-\frac{1}{2}\right)^{2}$ guarantees that a bad bureaucrat is fully loyal in equilibrium when a populist politician is in office in the second period, whereas a good bureaucrat may or may not implement the populist desired policy depending on the state. For example, if $q=\frac{1}{2}$ then obviously the bad bureaucrat is always loyal for every $R(\bar{R}=0)$, whereas a good bureaucrat would choose $q$ in the second period with probability 1 only for $R>\frac{1}{4}$.

At the opposite extreme of $q=1$ the bound $\bar{R}$ above which bad bureaucrats are loyal is $\frac{1}{4}$, whereas for a good bureaucrat loyal behavior is obtained for every realization of the state when $R>1$. Thus:

\footnotetext{
${ }^{10}$ All proofs in the appendix.
} 
Remark. For every value of $q \in\left[\frac{1}{2}, 1\right]$ there exists a range of values of $R\left(R \in\left(\bar{R}, q^{2}\right)\right)$ for which the populist strictly prefers a bad bureaucrat. In such a range, the populist politician always fires a bureaucrat when known to be good at the beginning of the second period.

The non-populist clearly prefers a good bureaucrat, since she always implements the correct policy. Bad bureaucrats try their best since they too want to match the state, but they can only do so in expectation. Therefore, the non-populist always fires a known bad bureaucrat at the beginning of the second period. The non-populist politician can't incentivize a bad bureaucrat to match the state since the bad bureaucrat lacks the relevant information.

As we show in the appendix, the populist fires good bureaucrats and retains bad bureaucrats even when $R<\left(q-\frac{1}{2}\right)^{2}$ and the bad bureaucrat chooses $x=\frac{1}{2}$. However, when $R<\left(q-\frac{1}{2}\right)^{2}$ the bad bureaucrat will not act loyally in the first period (see Lemma A.2). Therefore we assume $R \geq\left(q-\frac{1}{2}\right)^{2}$ for the rest of the paper.

\subsection{First Period}

Given any value of $R$ such that in the second period the strict preferences described above exist, the incentive to feign loyalty can be characterized as follows:

Lemma 2. Let the first period bureaucrat be good and the first period politician be populist. Assume the populist fires any bureaucrat who does not implement $x^{1}=q$. Then there exists an interval $\left[\underline{\omega^{1}}, \overline{\omega^{1}}\right]^{11}$ such that if $\omega^{1} \in\left[\underline{\omega^{1}}, \overline{\omega^{1}}\right]$, the bureaucrat will implement $x^{1}=q$; and $x^{1}=\omega^{1}$ otherwise.

Lemma 3. Let the first period bureaucrat be bad and the first period politician be populist. Assume the populist fires any bureaucrat who does not implement $x^{1}=q$. Then there exists a threshold $\hat{R}<q^{2}$ such that if $R \geq \hat{R}$, the bureaucrat will implement $x^{1}=q$ and $x^{1}=\frac{1}{2}$ otherwise.

\footnotetext{
${ }^{11} \underline{\omega^{1}}=\max \left\{0, q-\sqrt{\frac{1}{12}(1-\gamma) \pi\left(12 q^{2}-12 q-8 R^{3 / 2}+3\right)+\frac{1}{12}(1-\gamma)+R(\pi(2 \sqrt{R}-1)+2)}\right\}$ when $q+\sqrt{R}<$ 1 and $\max \left\{0, q-\sqrt{\frac{1}{12}\left((1-\gamma) \pi\left(4 q^{3}-4 R^{3 / 2}-1\right)+(1-\gamma)+12 R(\pi(\sqrt{R}-q)+2)\right)}\right\}$ when $q+\sqrt{R} \geq 1$. $\overline{\omega^{1}}=$ $\min \left\{1, q+\sqrt{\frac{1}{12}(1-\gamma) \pi\left(12 q^{2}-12 q-8 R^{3 / 2}+3\right)+\frac{1}{12}(1-\gamma)+R(\pi(2 \sqrt{R}-1)+2)}\right\}$ when $q+\sqrt{R}<1$ and 1 when $q+\sqrt{R} \geq 1$
} 
Note that $\hat{R}$ may be different from $\bar{R}$, and could even be larger than $\bar{R}$ (but always less than $q^{2}$, ). The bad bureaucrat's continuation value will take into account the probability that the second period politician is a populist vs non-populist. In particular, the bad bureaucrat will only receive second period rents when the second period politician is a populist. Further, she is better off with a good bureaucrat when the second period politician is a non-populist. Therefore when the probability of a second period populist is very low, the bad bureaucrat's threshold for acting loyally in the first period is higher than the second period threshold.

Define a loyal equilibrium as one where a bad bureaucrat implements the populist policy in the first period when a populist is in power.

Proposition 1. Let $R \geq \hat{R}$. Then a loyal equilibrium exists, where

\section{Second Period}

- Behavior is as described in Lemma 1.

- At the beginning of the period, populist politicians fire bureaucrats known to be good and non-populists politicians fire bureaucrats known to be bad, but both types retain bureaucrats who pooled in the first period.

\section{First Period}

- If $P_{p}^{1}$, bad bureaucrats implement $x^{1}=q$.

- If $P_{n}^{1}$, bad bureaucrats implement $x^{1}=\frac{1}{2}$.

- If $P_{p}^{1}$, good bureaucrats implement $x^{1}=q$ if $\omega^{1} \in\left[\underline{\omega^{1}}, \overline{\omega^{1}}\right]$ and $x^{1}=\omega^{1}$ otherwise.

- If $P_{n}^{1}$, good bureaucrats implement $x^{1}=\omega^{1}$.

- Populists retain bureaucrats at the end of the period if they implement $x^{1}=q$ and fire all others.

- Non-populists retain bureaucrats at the end of the period if they implement $x^{1}=\omega^{1}$ and fire all others. 
Good bureaucrats are willing to implement the populist policy when the policy loss is outweighed by first period office rents and the second period utility of being retained. This second period utility is a function of the likelihood a populist is in power next period, the likelihood a bad bureaucrat is hired, as well as office rents. Crucially, there always exists an interval where the good bureaucrat is willing to feign loyalty to the populist politician. We show below how this interval changes as parameters change, but it always exists.

With the equilibrium established, we can now see which institutional features make acting sincerely more or less likely (more or less likely in the sense that the range of values for $\omega^{1}$ that will lead to the good bureaucrat implementing the loyalist policy in the first period grows or shrinks).

Proposition 2. The probability a good bureaucrat feigns loyalty is

\section{Decreasing in $\gamma$.}

2. Increasing in $\pi$ when $\gamma \leq \frac{12 R(q+\sqrt{R})}{4 q^{3}+4 R^{3 / 2}-1}$ and $q \geq \frac{1}{2^{2 / 3}}$ and decreasing in $\pi$ otherwise.

\section{Increasing in $R$.}

\section{Decreasing in $q$.}

Intuitively, when the rents of office are higher and the populist policy is less extreme ( $q$ closer to $\frac{1}{2}$ ) the good bureaucrat has a greater incentive to feign loyalty to the populist. The comparative statics with respect to $\gamma$ is also easy to understand: it is when the replacement pool is of lower quality that a good bureaucrat has higher policy-utility motivation to feign loyalty.

It is not surprising that increasing $R$ will increase the probability of feigning loyalty. However, it is not just the direct effect of receiving rents today. It also makes it more desirable to be in office under a non-populist. Increasing rents has a direct effect of making feigning loyalty today more appealing, but the indirect effect of the stick-it-out phenomenon increases the probability of feigning loyalty further.

The most intricate effects to consider are those concerning $\pi$ : a higher probability of a populist in the future increases the incentives for the good bureaucrat to feign loyalty when the 


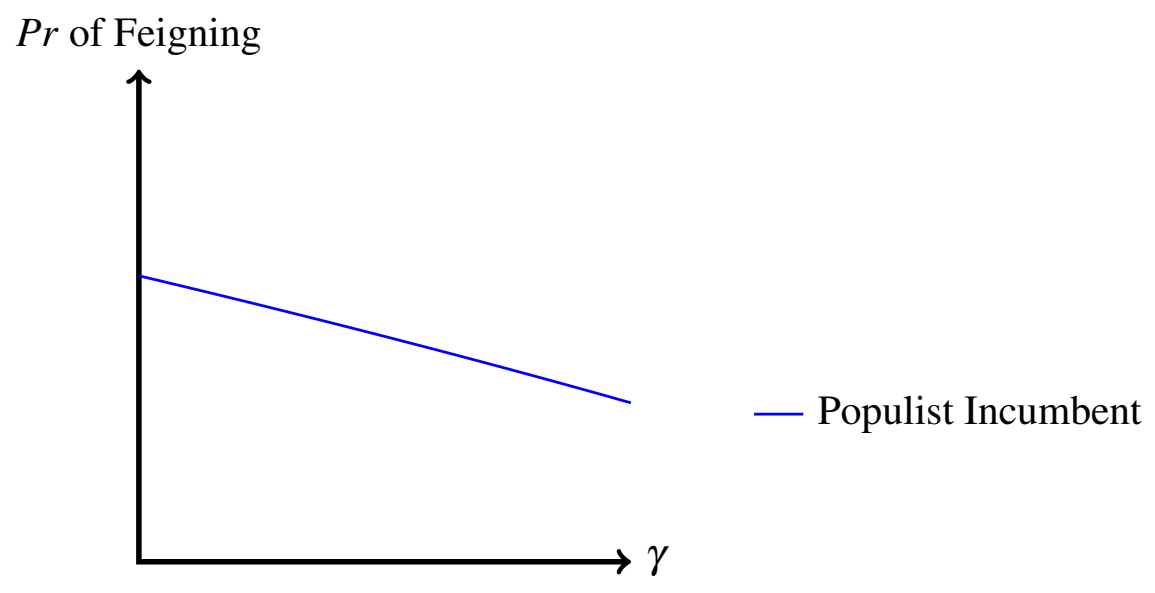

Figure 1: Probability of Feigning Loyalty by $\gamma$

expected policy-utility consequences in second period from being fired are highest, namely when the replacement pool is not great and the populist policy is worse in expectation. When the replacement pool is good, however, (a measure of strong bureaucracy) and the populist policy is not extreme then the current utility consequences have a higher weight in the decision. In this case, higher $\pi$ reduces the chances to obtain office rents in second period by sticking out and induces more sincere policymaking. She is guaranteed office rents in the next period only if the politician is non-populist. This makes staying in office more valuable to a bureaucrat when the chance of a second period populist is low. Strong bureaucracies with high chances of a non-populist induce a stick-it-out effect. When bureaucracies are weak, however, the second period policy loss from a non-expert combined with a populist is more salient and this induces the expert to feign loyalty. Summing up, feigning loyalty is more likely with strong bureaucracies and a low chance of a populist, but also when the bureaucracy is weak and there is a high chance of a populist - the two extremes.

The probability of feigning loyalty is decreasing in the extremism of the populist. However, the cross partial is negative. ${ }^{12}$ Extremism makes feigning loyalty less likely, but a higher chance of a bad type mitigates that decrease. This again shows how good types are particularly concerned with the bad bureaucrat/populist leader combination.

\footnotetext{
12

$$
\frac{\partial^{2} \operatorname{Pr}(F)}{\partial q \partial \gamma}=\frac{\sqrt{3} \pi\left(-4((1-\gamma)-6) \pi q^{2} R^{3 / 2}+(1-\gamma) q^{2}\left(\pi\left(4 q^{3}-1\right)+1\right)-R\left(20 \pi q^{3}+\pi-48 q^{2}\right)-4 \pi R^{5 / 2}+R\right)}{2\left((1-\gamma) \pi\left(4 q^{3}-1\right)-4((1-\gamma)-3) \pi R^{3 / 2}+(1-\gamma)-12 R(\pi q-2)\right)^{3 / 2}}
$$
}




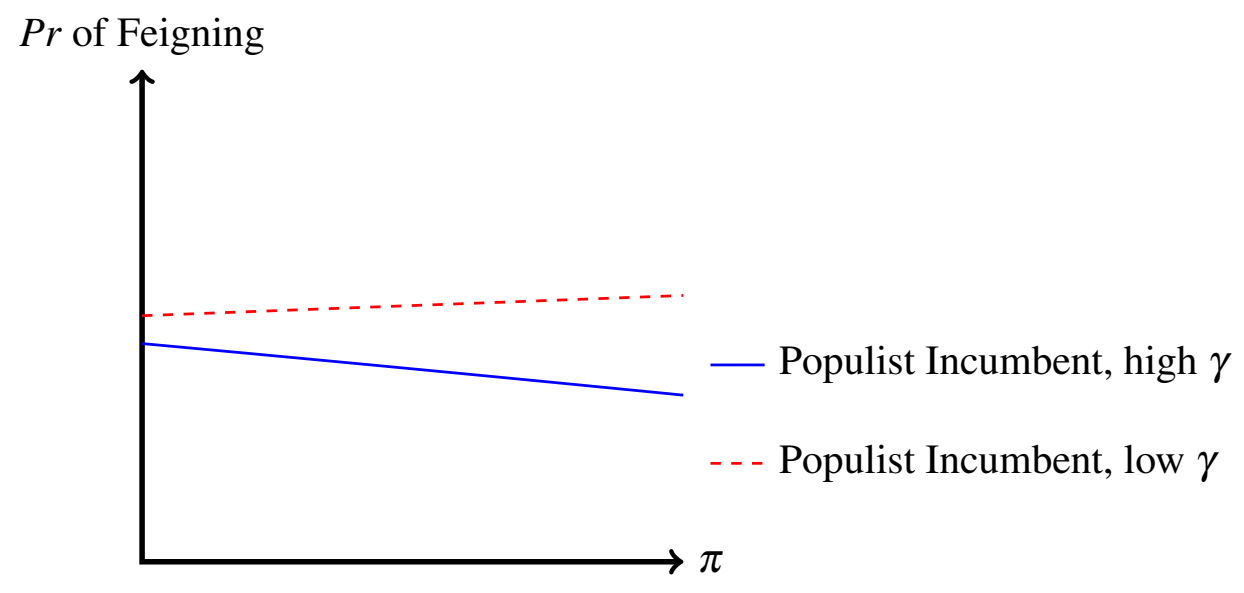

Figure 2: Probability of Feigning Loyalty by $\pi$

\section{Bureaucratic Turnover}

We can now use the bureaucrats' equilibrium strategies to learn about expected bureaucratic turnover. Note that turnover happens with positive probability when the good bureaucrat's equilibrium strategy is to implement the sincere policy.

The ex-ante probability to observe turnover at the end of first period is the probability of sincere policy making by a good bureaucrat when the incumbent is populist plus the probability of bad bureaucrat when the incumbent is non-populist.

Lemma 4. The ex-ante probability of first period bureaucratic turnover is

$$
\begin{aligned}
& \pi \cdot \gamma \cdot\left(q-\sqrt{\frac{1}{12}\left((1-\gamma) \pi\left(4 q^{3}-4 R^{3 / 2}-1\right)+(1-\gamma)+12 R(\pi(\sqrt{R}-q)+2)\right)}\right) \\
& +(1-\pi) \cdot(1-\gamma)
\end{aligned}
$$

It is useful to decompose the ex-ante probability into the conditional probability of turnover given a populist in office and the conditional probability of turnover given a non-populist in office. The two probabilities are 


$$
\left.\tau_{p}:=\gamma \cdot\left(q-\sqrt{\frac{1}{12}\left((1-\gamma) \pi\left(4 q^{3}-4 R^{3 / 2}-1\right)+(1-\gamma)+12 R(\pi(\sqrt{R}-q)+2)\right.}\right)\right)
$$

and

$$
\tau_{n}:=(1-\gamma) .
$$

With these probabilities, we can now show when we expect to see more turnover under populists and when we expect to see more turnover under non-populists:

Proposition 3. Turnover under a populist $\tau_{p}$ is

- Increasing in $\gamma$.

- Increasing in $\pi$ when $\gamma \geq \frac{12 R(q+\sqrt{R})}{4 q^{3}+4 R^{3 / 2}-1}$ and decreasing otherwise.

- Increasing in $q$.

- Decreasing in $R$.

Turnover under a non-populist $\tau_{n}$ is

- Decreasing in $\gamma$

- Invariant in $\pi$ and $q$.

With high $\pi$ and high $\gamma$ we know that feigning incentives are low, and hence turnover at end of first period is higher in equilibrium. There is a direct effect of a higher proportion of good bureaucrats increasing turnover under a populist. There is also a secondary effect pushing good bureaucrats to feign loyalty less often, which also lowers the amount of turnover. When $\gamma$ is low, however, the opposite holds. There are more bad bureaucrats who will be retained by populists, and good bureaucrats will feign loyalty more often. Both of these forces make turnover less likely under a populist. 


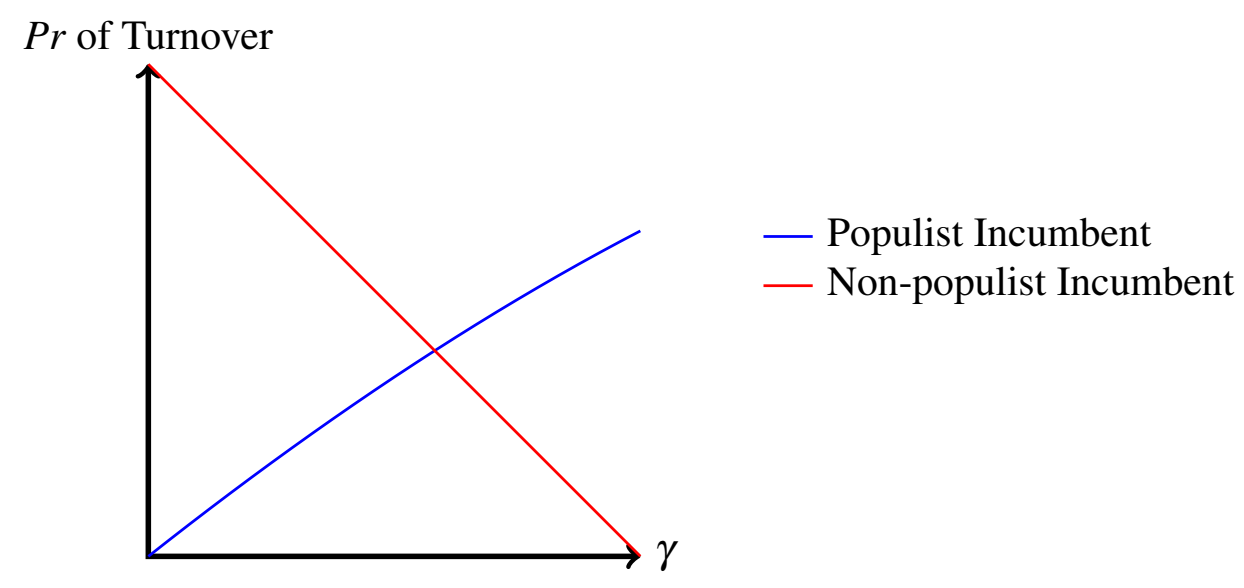

Figure 3: Probability of Turnover by $\gamma$

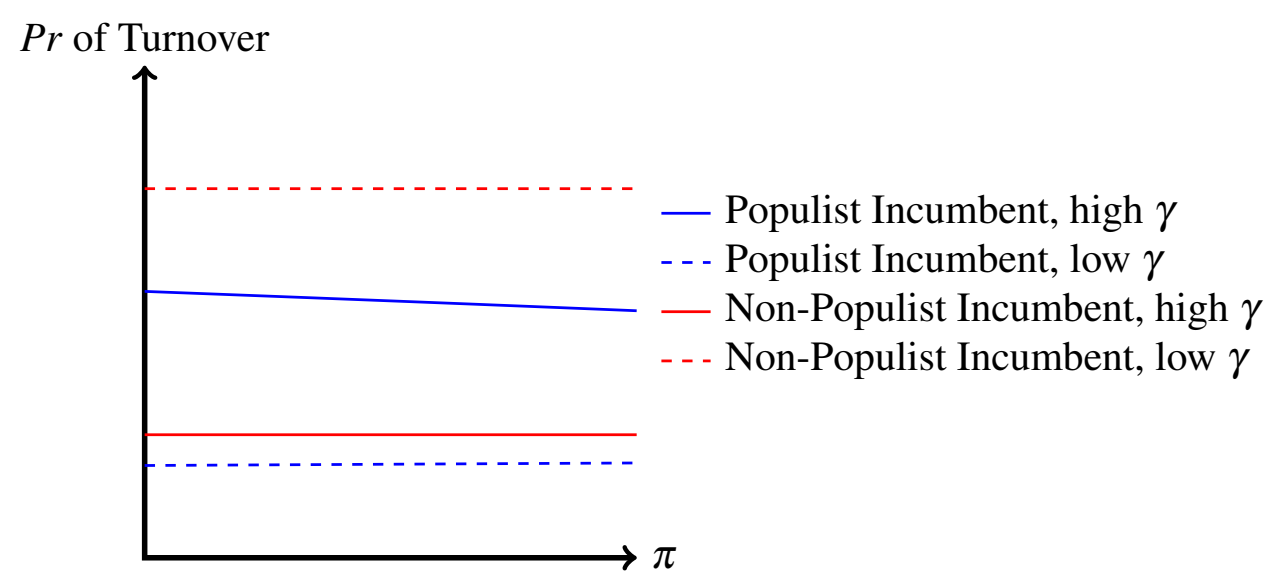

Figure 4: Probability of Turnover by $\pi$

A non-populist is more likely to fire the bureaucrat when $\gamma$ is low. Because a good bureaucrat will always perfectly reveal her type under a non-populist, the proportion of good bureaucrats is all that determines the turnover probability. Figures 3 and 4 illustrate the difference in turnover probabilities for populists versus non-populists.

\section{Extensions}

\subsection{Civil Service Protections}

We now study an extension with a simple parameterization of civil service strength. When politicians try to fire bureaucrats, they succeed with probability $\phi$ and fail with probability $1-\phi$. If they fail, 
the bureaucrat simply stays in office as if she was retained. A high $\phi$ means the politician has lots of leeway to fire bureaucrats; a low $\phi$ means civil service protections are high and the bureaucrat is insulated from political interference. ${ }^{13}$

Intuitively, one may think that strong civil service protections will allow the good bureaucrats more leeway in opposing populist policies. Indeed, we find that this is the case. However, as the next proposition makes clear, the good bureaucrat may now engage in strategic behavior when the incumbent is non-populist. Let us begin this analysis by first observing the changes in second period behavior:

Lemma 5. Let there be a populist in office in the second period and let firings be successful with probability $\phi$. Then a bad bureaucrat will implement $x^{2}=q$ if $R \geq \frac{\left(q-\frac{1}{2}\right)^{2}}{\phi}$ and a good bureaucrat will implement $x^{2}=q$ if $\omega^{2} \in[\max \{q-\sqrt{\phi R}, 0\}, \min \{q+\sqrt{\phi R}, 1\}]$.

Similar to the baseline case, we will restrict attention to the case where $R \geq \frac{\left(q-\frac{1}{2}\right)^{2}}{\phi}$ and $\{q+$ $\sqrt{(1-\phi) R} \geq 1$. For simplicity, we assume that if a bureaucrat's first period firing is unsuccessful, she cannot be fired at the beginning of the second period.

Proposition 4. Let there be a populist in office in the first period and let firings succeed with probability $\phi$. Then if the bureaucrat is bad, she implements $x^{1}=q$. If the bureaucrat is good she feigns loyalty and implements $x^{1}=q$ if

$$
\omega^{1} \geq q-\sqrt{\begin{array}{r}
\frac{1}{12} \phi\left(\gamma(\pi(4 q(-2 q+\sqrt{R \phi}+1)+4 R \phi-4 \sqrt{R \phi}+1)-1)+3 \pi(1-2 q)^{2}+1\right) \\
-\frac{1}{3}(\phi-1)\left(-p\left(-3 q R \phi+(q-1)^{3}+2(r \phi)^{3 / 2}\right)-6 R\right)+\frac{1}{3}\left(q^{3}-3 q^{2}+q(3-3 R \phi)+2(R \phi)^{3 / 2}+3 R-1\right)+R
\end{array}}
$$

otherwise she acts sincerely and implements $x^{1}=\omega^{1}$.

Further, this threshold is greater than the baseline threshold.

Let there be a non-populist in office in the first period. Then if the bureaucrat is bad, she

\footnotetext{
${ }^{13}$ This parameterization is also used for civil service strength in Gibbs (2020) and for tenure security in Gailmard and Patty (2007).
} 
implements $x^{1}=\frac{1}{2}$. If the bureaucrat is good she feigns loyalty and implements $x^{1}=\frac{1}{2}$ if

$$
\begin{aligned}
\omega^{1} \in & {\left[\frac{1}{2}-\sqrt{\left(\frac{1}{12}\left(\gamma\left(\pi\left(4(\phi-1)\left(q((q-3) q+3)-(R \phi)^{3 / 2}\right)-5 \phi+4\right)+\phi\right)+\phi(12(\pi-2) R+\pi-1)\right)\right)},\right.} \\
& \left.\frac{1}{2}+\sqrt{\left(\frac{1}{12}\left(\gamma\left(\pi\left(4(\phi-1)\left(q((q-3) q+3)-(R \phi)^{3 / 2}\right)-5 \phi+4\right)+\phi\right)+\phi(12(\pi-2) R+\pi-1)\right)\right)}\right]
\end{aligned}
$$

otherwise she acts sincerely and implements $x^{1}=\omega^{1}$.

Because a good bureaucrat may now survive into the next period even when they do not match policy to the state, they have an incentive to act like a bad bureaucrat even with an incumbent non-populist. Therefore experts may now feign loyalty under both types of politicians.

A good bureaucrat can get first-period office rents and the optimal policy purely by acting sincerely. However, if the incumbent is non-populist but the chance of a second period populist is

high, the good bureaucrat chooses $\frac{1}{2}$ more often. She is sometimes willing to trade-off policy and possibly losing rents today for the chance of avoiding a severe second period policy loss. Note that protections must be sufficiently high for the bureaucrat to make this trade-off. If protections are not high enough, the good bureaucrat will always act sincerely under a non-populist.

In general, there is a trade-off with civil service protections in confronting populists. Strong protections mean experts can stay in office even when opposing populist policies. This is clearly good for welfare and lessens the probability of feigning loyalty under an incumbent populist (the resistance phenomenon). However, strong protections also encourage distorted policymaking under non-populist incumbents in periods where a shift to populism is expected.

Strong protections also mean second period non-populists may struggle to fire bad bureaucrats. Therefore bad bureaucrats who were retained in the first period will survive into the second period even under non-populists and implement suboptimal policy.

\subsection{Rehiring}

Consider a scenario from 2020 where President Trump considered firing the director of the U.S. National Institute of Allergy and Infectious Diseases, Doctor Fauci. As a well respected, long-time 
civil servant, it is likely that Fauci would have been rehired if Trump lost the election. If a good bureaucrat can signal that she is a good type by not feigning loyalty and be guaranteed to be hired by a second period non-populist, how would this affect her first period behavior?

Proposition 5. Let second period politicians be able to rehire fired first period bureaucrats. Then good bureaucrats will feign loyalty under a first period populist if

$$
\omega^{1} \geq q-\sqrt{\frac{1}{3} \pi\left((1-\gamma) q^{3}-3 q R+(\gamma+2) R^{3 / 2}+3 R\right)+R}
$$

. Behavior is exactly the same as in the baseline case under a first period non-populist.

$$
\text { Further } q-\sqrt{\frac{1}{3} \pi\left((1-\gamma) q^{3}-3 q R+(\gamma+2) R^{3 / 2}+3 R\right)+R} \geq \underline{\omega^{1}} .
$$

Note that compared to the baseline case, the utility of feigning loyalty has stayed the same, but the utility of acting sincerely has increased. Therefore the good bureaucrat will feign loyalty less often than in the baseline case. Consequently, $q-\sqrt{\frac{1}{3} \pi\left((1-\gamma) q^{3}-3 q R+(\gamma+2) R^{3 / 2}+3 R\right)+R} \geq$ $\omega^{1}$. However, even with guaranteed rehiring, there is still an incentive to feign loyalty. The guaranteed rehiring removes the stick-it-out effect as the good bureaucrat is guaranteed second period office rents under a non-populist, but the desire to avoid a populist+bad bureaucrat combination still exists.

\subsection{Policy Motivation}

We now allow the good bureaucrat to care more about policy than the bad bureaucrat. ${ }^{14}$ The bureaucrat now cares more about policy than rents. We keep the bad bureaucrat's per-period utility the same as in the baseline case and let the good bureaucrat's per-period utility function now be

$$
U_{g}=R \cdot I-\alpha(x-\omega)^{2}
$$

where $\alpha \geq 1$.

\footnotetext{
${ }^{14}$ Gailmard and Patty (2007) provides a microfoundation for why we might expect experts to have higher policy motivation than non-experts. Policy-motivated bureaucrats have more of an incentive to develop expertise precisely because they care more about matching policy to the state of the world.
} 
Note that it is not obvious ex-ante whether this should make the expert bureaucrat more or less likely to feign loyalty. On the one hand, feigning loyalty is now worse from a policy perspective; it costs more today to not enact the sincere policy. However, it also makes a second period bad bureaucrat worse for the expert. Therefore there is a greater incentive for the first period expert to stay in office for the second period.

The second period proceeds exactly the same as in the original game. The only change is that expert's equilibrium cutoff for implementing the populist policy is now

$$
\omega^{2} \geq 1-\sqrt{\frac{R}{\alpha}}
$$

As long as $\alpha>1$, this new cutoff is strictly greater than the cutoff in the baseline model. Strong policy motivation pushes experts to make second period policy sincerely with a higher probability.

Let $\underline{\omega}^{1 \alpha}$ be the feigning loyalty cutoff for the modified game. The next proposition shows that the second period result also holds in the first period:

Proposition 6. Let good bureaucrats have a per period utility function $U_{g}=R \cdot I-\alpha(x-\omega)^{2}$, where $\alpha \geq 1$. Then the cutoff for feigning loyalty $\underline{\omega}^{1 \alpha} \geq \underline{\omega}^{1}$.

Further, the probability of feigning loyalty is decreasing in $\alpha$.

This result shows that implementing the correct policy today is more important to experts than staying in office. When policy motivation is high, they are more willing to live with the possibility of a loyalist tomorrow in order to get today's policy right. When rents are less important, the stick-it-out effect has less bite. The first period good bureaucrat does not care if she is the specific expert in office in the second period because she does not care about accruing the office rents. If we think that more expert bureaucrats are also highly motivated by policy outcomes, then we should expect to see a lot of bureaucratic policy pushing against populist aims and a lot of turnover in countries with strong bureaucracies. 


\section{Concluding Remarks and Future Research}

We have analyzed a model of bureaucratic policy making under populism. We have shown that even short-term populism can lower the expertise of the bureaucracy and create poor policy implementation. Bellodi, Morelli and Vannoni (2021) show that all such predictions hold for Italian municipality elections, using a close election regression discontinuity design.

While we have not analyzed it in this paper, it seems reasonable that policy feedback effects from choosing inefficient policies could harm the reelection chances of a populist. For example, Alabrese and Fetzer (2018) shows that places that voted for Brexit have soured on the policy after significant economic hardship. However it is important to keep in mind that even if these feedback effects harm populist reelection chances, they harm them because of poor policy. That is, just because populist politicians may have a short shelf-life does not mean they do not do damage while they have the chance. Part of this damage comes from populists pushing experts to disregard their own expertise and implement wrong policies.

Our model and results have implications for a discussion on control mechanisms that a populist leader can adopt to alter incentives: politicians can have two possible levers to influence bureaucratic behavior: they can change the salary $(R)$ or invest in better screening and training of candidates $(\gamma)$. From a populist's perspective, both raising the salary and decreasing training will have the desired affect of more populist policy implementation. But raising bureaucratic salaries goes against anti-elite populist messaging. Reducing funding for training and screening, however, is in keeping with anti-elite campaign promises. If populists expect to stay in power, then we should observe a hollowing out of bureaucratic institutions. As our model shows, populist do not need to fill the bureaucracy with populist ideologues; they simply need to make sure agencies are staffed with non-experts.

This also raises a possible downside to increasing salaries for bureaucrats. While increasing salaries may attract more qualified candidates, it may also make these candidates more susceptible to capture by populist politicians. This suggests that higher salaries should also be combined with 
screening for more policy-motivated bureaucrats.

The setup analyzed in this paper can be extended in multiple ways. For example, a very similar model can also be applied to a party's selection of its candidate. Parties may want a candidate to implement a certain policy (perhaps due to donor concerns, voter turnout effects, or other possible reasons). The same forces would apply; a non-expert politician would be easier to convince to implement the party's policy. The party would have a harder time controlling an expert candidate.

Future research could examine whether the distortions studied in this paper or those proposed in the party candidate model are affected by the presence of a proportional representation electoral system or separation of powers. These two institutional variables induce greater need of compromise or divided government respectively, and this may affect the ability of parties or populists to influence their agents. Future research could also elucidate on the effects of existence of populists on both sides of the political spectrum. This, we conjecture, may increase on balance the desirability of civil service reform.

\section{Acknowledgments}

We wish to thank Thomas Fujiwara, Navin Kartik, Stephane Wolton, two anonymous referees and participants at the Virtual Formal Theory Workshop for helpful comments and suggestions. We are grateful to the ERC, advanced grant 694583. The usual disclaimer applies.

\section{References}

Acemoglu, Daron, Georgy Egorov and Konstantin Sonin. 2013. "A Political Theory of Populism." The Quarterly Journal of Economics 128(2):771-805.

Alabrese, Eleonora and Thiemo Fetzer. 2018. "Who is NOT voting for Brexit anymore?". Technical report Competitive Advantage in the Global Economy (CAGE).

Ashworth, Scott and Kenneth W Shotts. 2010. "Does Informative Media Commentary Reduce Politicians' Incentives to Pander?" Journal of Public Economics 94(11-12):838-847. 
Barbash, Fred and Deanna Paul. 2019. "The real reason the Trump administration is constantly losing in court." The Washington Post .

URL: $\quad$ https://www.washingtonpost.com/world/national-security/the-real-reason-presidenttrump-is-constantly-losing-in-court/

Barnes, Julian E. and Maggie Haberman. 2020. “Trump Names Richard Grenell as Acting Head of Intelligence." The New York Times .

URL: $\quad$ https://www.nytimes.com/2020/02/19/us/politics/dni-national-intelligence-directorgrenell.html

Bellodi, Luca, Massimo Morelli and Matia Vannoni. 2021. "The Costs of Populism for the Bureaucracy and Government Performance." Working Paper .

URL: https://www.dropbox.com/sh/8rxljlnr4xkcphf/AADFI4UdD5REOsPrzvfpzLt4a

Bolton, Alexander, John M De Figueiredo and David E Lewis. 2021. "Elections, Ideology, and Turnover in the US Federal Government." Journal of Public Administration Research and Theory 31(2):451-466.

Callander, Steven. 2008. “A Theory of Policy Expertise.” Quarterly Journal of Political Science 3(2):123-140.

Cameron, Charles M and John M de Figueiredo. 2020. "Quitting in Protest: Presidential Policymaking and Civil Service Response." Quarterly Journal of Political Science 15(4):507-538.

Chesterley, Nicholas and Paolo Roberti. 2018. "Populism and Institutional Capture." European Journal of Political Economy 53:1-12.

de Figueiredo Jr, Rui JP. 2002. "Electoral competition, political uncertainty, and policy insulation.” American Political Science Review pp. 321-333.

De Mesquita, Ethan Bueno and Amanda Friedenberg. 2011. "Ideologues or Pragmatists?” Journal of the European Economic Association 9(5):931-951. 
Dixit, Avinash, Gene M Grossman and Faruk Gul. 2000. "The dynamics of political compromise." Journal of political economy 108(3):531-568.

Egorov, Georgy and Konstantin Sonin. 2011. "Dictators and their viziers: Endogenizing the loyaltycompetence trade-off." Journal of the European Economic Association 9(5):903-930.

Epstein, David and Sharyn O’Halloran. 1994. “Administrative Procedures, Information, and Agency Discretion.” American Journal of Political Science 38(3):697-722.

Epstein, David and Sharyn O'Halloran. 1999. Delegating Powers: A Transaction Cost Politics Approach to Policy Making Under Separate Powers. Cambridge University Press.

Fox, Justin and Kenneth W Shotts. 2009. "Delegates or trustees? A theory of political accountability." The Journal of Politics 71(4):1225-1237.

Fox, Justin and Stuart V Jordan. 2011. "Delegation and Accountability." The Journal of Politics 73(3):831-844.

Funke, Manuel, Moritz Schularick and Christoph Trebesch. 2021. Populist Leaders and the Economy. Technical report CEPR Discussion Paper.

Gailmard, Sean and John W Patty. 2007. "Slackers and Zealots: Civil Service, Policy Discretion, and Bureaucratic Expertise.” American Journal of Political Science 51(4):873-889.

Gailmard, Sean and John W Patty. 2012. "Formal Models of Bureaucracy." Annual Review of Political Science 15:353-377.

Ghosh, Sambuddha and Vinayak Tripathi. 2012. "Ideologues Beat Idealists.” American Economic Journal: Microeconomics 4(2):27-49.

Gibbs, Daniel. 2020. “Civil service reform, self-selection, and bureaucratic performance.” Economics \& Politics . 
Gratton, Gabriele, Luigi Guiso, Claudio Michelacci and Massimo Morelli. 2021. "From Weber to Kafka: Political Instability and Overproduction of Laws.” American Economic Review .

Heer, Jeet. 2019. “Trump Isn’t Totally Wrong About the Deep State.” The Nation .

URL: https://www.thenation.com/article/archive/trump-deep-state/

Huber, John D and Charles R Shipan. 2002. Deliberate Discretion?: The Institutional Foundations of Bureaucratic Autonomy. Cambridge University Press.

Lee, Barton E. 2020. "Feigning Politicians.” Available at SSRN 3491611 .

Levy, Gilat, Ronny Razin and Alwyn Young. 2019. "Misspecified Politics and the Recurrence of Populism.” Working Paper .

Li, Christopher. 2021. “Indirect Accountability of Political Appointees." Journal of Theoretical Politics 33(3):383-396.

Luo, Zhaotian and Adam Przeworski. 2020. "Democracy and its vulnerabilities: Dynamics of democratic backsliding." Working Paper .

Maskin, Eric and Jean Tirole. 2004. "The Politician and the Judge: Accountability in Government." American Economic Review 94(4):1034-1054.

McCubbins, Mathew D, Roger G Noll and Barry R Weingast. 1987. "Administrative Procedures as Instruments of Political Control." Journal of Law Econ. \& Org. 3:243.

McCubbins, Matthew D, Roger G Noll and Barry R Weingast. 1989. "Structure and Process, Politics and Policy: Administrative Arrangements and the Political Control of Agencies." Va. L. Rev. $75: 431$.

Morelli, Massimo, Antonio Nicoló and Paolo Roberti. 2021. "A Commitment Theory of Populism.” Working Paper.

URL: https://www.dropbox.com/sh/tza2r5g9ohxghu0/AAA-kdrHVj2glReZMHB5OyPea 
Morelli, Massimo and Richard Van Weelden. 2013. "Ideology and Information in Policymaking." Journal of Theoretical Politics 25(3):412-439.

Morris, Stephen. 2001. “Political Correctness.” Journal of political Economy 109(2):231-265.

Mudde, Cas. 2004. “The Populist Zeitgeist.” Government and Opposition 39(4):541-563.

Müller, Jan-Werner. 2017. What is populism? Penguin UK.

Peters, B Guy and Jon Pierre. 2019. "Populism and Public Administration: Confronting the Administrative State.” Administration \& Society 51(10):1521-1545.

Sasso, Greg. 2020. “Delegation and Political Turnover.” Journal of Theoretical Politics 32(2):262268.

URL: https://journals.sagepub.com/doi/10.1177/0951629819895596

Sciutto, Jim. 2020. "Exclusive: Vindman to retire from military. His lawyer blames White House 'campaign of bullying, intimidation and retaliation'.' CNN .

URL: $\quad$ https://www.cnn.com/2020/07/08/politics/vindman-retiring-alleged-white-houseretaliation/index.html

Tenpass, Kathryn Dunn. 2018. "Why is Trump's staff turnover higher than the 5 most recent presidents?" The Brookings Institute .

URL: https://www.brookings.edu/research/why-is-trumps-staff-turnover-higher-than-the-5-mostrecent-presidents/

Ting, Michael M. 2009. “Organizational Capacity.” The Journal of Law, Economics, \& Organization 27(2):245-271.

Ujhelyi, Gergely. 2014. “Civil Service Reform.” Journal of Public Economics 118:15-25.

Vlaicu, Razvan and Alexander Whalley. 2016. "Hierarchical Accountability in Government." Journal of Public Economics 134:85-99. 
Yazaki, Yukihiro. 2018. "The Effects of Bureaucracy on Political Accountability and Electoral Selection." European Journal of Political Economy 51:57-68.

Zakharov, Alexei V. 2016. “The Loyalty-competence trade-off in dictatorships and outside options for subordinates." The Journal of Politics 78(2):457-466. 


\section{A Proofs}

Proof of Lemma 1. Recall the off-path beliefs: Let populist politicians believe that if $x^{t}$ is neither

equal to $q$ nor $\frac{1}{2}$ then the bureaucrat is good with probability 1 . Let non-populist politicians believe that if $x^{t} \neq \omega^{t}$, then the bureaucrat is good with probability 0 .

Populists: First we look at behavior under a populist and assume the populist fires any bureaucrat who implements a policy other than $q$. Because of the off-path beliefs, the bad bureaucrat will be fired for any $x^{2} \neq q$. The best she can do policy wise is to choose $x^{2}=\frac{1}{2}$. For the bad bureaucrat to choose $x^{2}=q$ over $x^{2}=\frac{1}{2}$, we need

$$
\begin{aligned}
R-E\left[(q-\omega)^{2}\right] & >-E\left[\left(\frac{1}{2}-\omega\right)^{2}\right] \\
R-\left(\frac{1}{3}-q+q^{2}\right) & \geq-\frac{1}{12} \\
R & \geq\left(q-\frac{1}{2}\right)^{2}
\end{aligned}
$$

The good bureaucrat conditions her policy choice on the state of the world. Note that it can clearly never be optimal for her to choose any policy other than $q$ or $\omega^{2}$ as she would be fired and would implement a suboptimal policy. Therefore her choice is between $q$ and $\omega^{2}$. She implements $x^{2}=q$ if

$$
\begin{gathered}
R-\left(q-\omega^{2}\right)^{2} \geq 0 \\
R \geq\left(q-\omega^{2}\right)^{2} \\
\omega^{2} \in[\max \{q-\sqrt{R}, 0\}, \min \{q+\sqrt{R}, 1\}]
\end{gathered}
$$

Finally, we check that the populist politician has no profitable deviations. Because firing and retaining is the last move of the game, it has no effect on future payoffs. Therefore there is no incentive to deviate from the conjectured equilibrium actions.

Non-populists: We now look at behavior under non-populists and assume they fire any 
bureaucrat who does not implement $x^{2}=\omega^{2}$. The good bureaucrat knows the state of the world, and can therefore always choose $x^{2}=\omega^{2}$ and be retained. The bad does not know the state of the world and therefore she can match policy to the state with probability 0 . Therefore, she will be fired with probability 1 and the best she can do is to choose $x^{2}=\frac{1}{2}$.

Finally, we check that the non-populist politician has no profitable deviations. Because firing and retaining is the last move of the game, it has no effect on future payoffs. Therefore there is no incentive to deviate from the conjectured equilibrium action.

Let $\bar{R}:=\left(q-\frac{1}{2}\right)^{2}$.

Given the above lemma, $\operatorname{Pr}\left(F^{2}\right)$, the probability of feigning loyalty in the second period by a good bureaucrat, is:

$$
\operatorname{Pr}\left(F^{2}\right)=\left\{\begin{array}{l}
2 \sqrt{R} \text { when } \sqrt{R} \leq 1-q \\
1-q+\sqrt{R} \text { when } q+\sqrt{R} \geq 1 \text { and } q-\sqrt{R} \geq 0 \\
1 \text { when } q+\sqrt{R} \geq 1 \text { and } q-\sqrt{R} \leq 0
\end{array}\right.
$$

Let $E U\left(F^{2}\right)$ be the ex-ante expected policy utility for all non-populist players when a good bureaucrat feigns loyalty in the second period.

$E U\left(F^{2}\right)=\operatorname{Pr}\left(F^{2}\right) \cdot E\left[-(q-\omega)^{2} \mid F\right]+\left(1-\operatorname{Pr}\left(F^{2}\right)\right) \cdot 0=\left\{\begin{array}{l}-\frac{2 R^{3 / 2}}{3} \text { when } q+\sqrt{R} \leq 1 \text { and } q-\sqrt{R} \geq 0 \\ -\frac{1}{3}\left(R^{3 / 2}+(1-q)^{3}\right) \text { when } q+\sqrt{R} \geq 1 \text { and } q-\sqrt{R} \geq 0 \\ -\frac{1}{3}-q+q^{2} \text { when } q+\sqrt{R} \geq 1 \text { and } q-\sqrt{R} \leq 0\end{array}\right.$

Denote the endpoints of the feigning loyalty interval by $\left[\underline{\omega^{2}}, \overline{\omega^{2}}\right]$ and the interval as $I_{\omega^{2}}$.

Lemma A.1. At the beginning of the second period, populist politicians fire bureaucrats believed to be good and non-populist politicians fire bureaucrats believes to be bad.

Proof of Lemma A.1. It is obvious that non-populists always want good bureaucrats. We need to show that a populist always prefers a bad to a good bureaucrat. This is clear when $R \geq \bar{R}$. We check 
for $R<\bar{R}$.

The populist's utility from a bad bureaucrat:

$$
E U_{p}(b)=-\left(q-\frac{1}{2}\right)^{2}
$$

There is no uncertainty over this utility because it is not state contingent.

Note that if $R<\bar{R}$, the probability a good bureaucrat chooses $x^{2}=q$ is always less than 1 .

The populist's expected utility from a good bureaucrat when $q+\sqrt{R} \leq 1$ :

$$
\begin{aligned}
E U_{p}(g) & =\operatorname{Pr}\left(F^{2}\right) \cdot 0-\left(1-\operatorname{Pr}\left(F^{2}\right)\right) E\left[\left(q-\omega^{2}\right) \mid \omega^{2} \notin I_{\omega^{2}}\right] \\
& =-(1-(q+\sqrt{R})) \cdot \frac{1}{3}\left((1-q)^{2}+(1-q) \sqrt{R}+R\right)-(q-\sqrt{R}) \frac{1}{3}\left(q^{2}+q \sqrt{R}+R\right) \\
& =-q^{2}+q+\frac{2 R^{3 / 2}}{3}-\frac{1}{3}
\end{aligned}
$$

Similar calculations show that the expected utility when $q+\sqrt{R} \geq 1$ is $-\frac{1}{3}\left(q^{3}-R^{3 / 2}\right)$. Note that if the populist always prefers a bad bureaucrat when $q+\sqrt{R} \geq 1$, it must also be true for when $q+\sqrt{R} \leq 1$.

Let $q+\sqrt{R} \geq 1$. Then the populist prefers a bad bureaucrat if

$$
-\left(q-\frac{1}{2}\right)^{2} \geq-\frac{1}{3}\left(q^{3}-R^{3 / 2}\right)
$$

This is always true for $R \leq \frac{1}{4}$, which is the greatest possible value of $\bar{R}$.

Lemma A.2. $R \geq \bar{R}$ is a necessary condition for a loyal equilibrium.

Proof. If $R<\bar{R}$, the bad bureaucrat's utility from choosing the populist policy is

$$
\begin{aligned}
U_{B}(q) & =R-\frac{1}{3}\left(1-3 q+3 q^{2}\right)+\pi\left(-\frac{1}{12}\right) \\
& +(1-\pi)\left(\operatorname{Pr}\left(F^{1}\right)\left(-\frac{1}{12}\right)+\left(1-\operatorname{Pr}\left(F^{1}\right)\right)\left(\gamma \cdot 0+(1-\gamma)\left(-\frac{1}{12}\right)\right)\right)
\end{aligned}
$$


where $\operatorname{Pr}\left(F^{1}\right)$ is the probability a good bureaucrat feigns loyalty in the first period. If a good bureaucrat would feign loyalty, then the second period non-populists retains all first period bureaucrats.

The bad bureaucrat's utility from choosing $x=\frac{1}{2}$ is

$$
\begin{aligned}
U_{B}\left(\frac{1}{2}\right) & =-\frac{1}{12}+\pi\left(\gamma\left(-\frac{1}{3}\left(R^{3 / 2}+(1-q)^{3}\right)\right)+(1-\gamma)\left(-\frac{1}{12}\right)\right) \\
& +(1-\pi)\left(\gamma \cdot 0+(1-\gamma)\left(-\frac{1}{12}\right)\right)
\end{aligned}
$$

We need to show that $U_{B}\left(\frac{1}{2}\right) \geq U_{B}(q)$. Note that bad bureaucrat's second period utility when choosing the populist policy is strictly decreasing in $\operatorname{Pr}\left(F^{1}\right)$. Therefore if $U_{B}\left(\frac{1}{2} \geq U_{B}(q)\right.$ when $\left(\operatorname{Pr}\left(F^{1}\right)=0\right.$, it will be true when $\left(\operatorname{Pr}\left(F^{1}\right)>0\right.$. Setting $\left(\operatorname{Pr}\left(F^{1}\right)=0\right.$, the 2nd period utility under a non-populist is the same in both cases. Therefore the bad bureaucrat will choose $\frac{1}{2}$ if

$$
\begin{aligned}
& -\frac{1}{12}+\pi\left(\gamma\left(-\frac{1}{3}\left(R^{3 / 2}+(1-q)^{3}\right)\right)+(1-\gamma)\left(-\frac{1}{12}\right)\right) \\
& \geq R-\frac{1}{3}\left(1-3 q+3 q^{2}\right)+\pi\left(-\frac{1}{12}\right)
\end{aligned}
$$

Because $R<\bar{R},-\frac{1}{12}>R-\frac{1}{3}\left(1-3 q+3 q^{2}\right)$. It is also true that $-\frac{1}{3}\left(R^{3 / 2}+(1-q)^{3}\right)>-\frac{1}{12}$ when $R<\bar{R}$. Therefore $U_{B}\left(\frac{1}{2}\right) \geq U_{B}(q)$.

From now on, we focus only on $R \geq \bar{R}$.

Proof of Lemma 2. Note that if the bureaucrat chooses $x^{1}=q$ she will be retained with certainty. If values of $\omega_{1}$ exist such that the good bureaucrat feigns loyalty, in such a "pooling" state of the world the bureaucrat is retained by the first period politician and the second period politician's posterior belief about the bureaucrat's type is still the prior, and hence the bureaucrat is retained also in second period.

When $R \geq \bar{R}$, the good bureaucrat's second period expected utility after being fired is $-\pi$. $(1-\gamma) \cdot\left(\frac{1}{3}-q+q^{2}\right)+\pi \cdot \gamma \cdot E U\left(F^{2}\right)-(1-\pi)(1-\gamma) \frac{1}{12}$ where $E U\left(F^{2}\right)$ depends on the cases as defined above. 
The second period expected utility after being retained: $\pi \cdot \operatorname{Pr}\left(F^{2}\right) \cdot\left(E\left[-(q-\omega)^{2} \mid F\right]+R\right)+$ $(1-\pi) \cdot(0+R)$.

The first period utility for feigning loyalty is $R-\left(q-\omega^{1}\right)^{2}$, and the first period utility for acting sincerely is 0 .

We start with the calculation for $q+\sqrt{R} \leq 1$ and $q-\sqrt{R} \geq 0$. The expert will feign loyalty if

$$
\begin{gathered}
R-\left(q-\omega^{1}\right)^{2}+\pi \frac{4 R^{3 / 2}}{3}+(1-\pi) R \geq-p \cdot(1-\gamma) \cdot\left(\frac{1}{3}-q+q^{2}\right)-\pi \cdot \gamma \cdot \frac{2 R^{3 / 2}}{3}-(1-\pi)(1-\gamma) \frac{1}{12} \\
\left(q-\omega^{1}\right)^{2} \geq R+\pi \frac{4 R^{3 / 2}}{3}+\pi(1-\gamma) \cdot\left(\frac{1}{3}-q+q^{2}\right) \\
+\pi \cdot \gamma \cdot \frac{2 R^{3 / 2}}{3}+(1-\pi)(1-\gamma) \frac{1}{12} \\
\omega^{1} \in q \pm \sqrt{\begin{array}{r}
\frac{1}{12}(1-\gamma) \pi\left(12 q^{2}-12 q-8 R^{3 / 2}+3\right) \\
+\frac{1}{12}(1-\gamma)+R(\pi(2 \sqrt{R}-1)+2)
\end{array}}
\end{gathered}
$$

However, there is also the constraint that the interval endpoints must be less than 1 and greater than 0 . Define $C$ as the expression after the \pm . The expert will feign loyalty if $\omega^{1} \in[\max \{q-$ $C, 0\}, \min \{q+C, 1\}]$. For the next case we do not state the 0 and 1 constraints, but they are implied.

Next, $q+\sqrt{R} \geq 1$ and $q-\sqrt{R} \geq 0$

$$
\begin{gathered}
R-\left(q-\omega^{1}\right)^{2}+\pi \frac{1}{3}\left(-3(q-1) R+(q-1)^{3}+2 R^{3 / 2}\right)+(1-\pi) R \\
\geq-\pi(1-\gamma) \cdot\left(\frac{1}{3}-q+q^{2}\right)-\pi \cdot \gamma \cdot \frac{1}{3}\left(R^{3 / 2}+(1-q)^{3}\right)-(1-\pi)(1-\gamma) \frac{1}{12} \\
\left(q-\omega^{1}\right)^{2} \geq R+\pi \frac{1}{3}\left(-3(q-1) R+(q-1)^{3}+2 R^{3 / 2}\right) \\
+\pi(1-\gamma) \cdot\left(\frac{1}{3}-q+q^{2}\right)+\pi \cdot \gamma \cdot \frac{1}{3}\left(R^{3 / 2}+(1-q)^{3}\right)+(1-\pi)(1-\gamma) \frac{1}{12} \\
\omega^{1} \in q \pm \sqrt{\frac{1}{12}\left((1-\gamma) \pi\left(4 q^{3}-4 R^{3 / 2}-1\right)+(1-\gamma)+12 R(\pi(\sqrt{R}-q)+2)\right)}
\end{gathered}
$$

For $q+\sqrt{R} \geq 1$ and $q-\sqrt{R} \leq 0$, the first period interval will also be $[0,1]$. Note that $R-(q-\omega)^{2} \geq 0$ for all $\omega$. Therefore implementing the populist policy in the first period gives a 
(weakly) positive utility to an expert. She is also guaranteed a (weakly) positive utility in the second period. By implementing $x^{1}=\omega^{1}$, she gets 0 in the first period and a negative expected second period utility. Therefore she will always implement the populist policy in the first period.

Define $\left[\underline{\omega^{1}}, \overline{\omega^{1}}\right]$ as the interval where if $\omega^{1} \in\left[\underline{\omega^{1}}, \overline{\omega^{1}}\right]$ an expert implements the populist policy in the first period.

Proof of Lemma 3. From Lemma A.2, we need only consider $R \geq \bar{R}$. We illustrate the proof for a specific case of $R \geq \bar{R}$, noting that the exact same procedure produces the same conclusions for the other cases of $R \geq \bar{R}$. Specifically, we show the case where $q+\sqrt{R} \geq 1$ and $q-\sqrt{R} \geq 0$.

Note that there is some probability that $\omega^{1} \in\left[\underline{\omega^{1}, \overline{\omega^{1}}}\right]$ and therefore a second period nonpopulist will retain the bad bureaucrat. The bad bureaucrat's payoff from choosing $x^{1}=q$ :

$$
\begin{aligned}
E U_{B}(q) & =R-\left(\frac{1}{3}-q+q^{2}\right)+\pi \cdot\left(R-\left(\frac{1}{3}-q+q^{2}\right)\right) \\
& +(1-\pi)\left[\operatorname{Pr}\left(F^{1}\right) \cdot \frac{-1}{12}+\left(1-\operatorname{Pr}\left(F^{1}\right)\right)\left((1-\gamma) \cdot \frac{-1}{12}+\gamma \cdot 0\right)\right]
\end{aligned}
$$

The bad bureaucrat's payoff from choosing $x^{1}=\frac{1}{2}$ is:

$$
\begin{aligned}
E U_{B}\left(\frac{1}{2}\right) & =-\frac{1}{12}+\pi \cdot\left((1-\gamma) \cdot-\left(\frac{1}{3}-q+q^{2}\right)+\gamma \cdot E U\left(F^{2}\right)\right)+(1-\pi)\left((1-\gamma) \cdot\left(-\frac{1}{12}\right)+\gamma \cdot 0\right) \\
& =-\frac{1}{12}-\pi \cdot(1-\gamma) \cdot\left(\frac{1}{3}-q+q^{2}\right)+\pi \cdot \gamma \cdot\left(-\frac{1}{3}\left(R^{3 / 2}+(1-q)^{3}\right)\right)-(1-\pi)(1-\gamma) \frac{1}{12}
\end{aligned}
$$

Therefore for the bad bureaucrat to choose $x^{1}=q$, we need $R$ large enough such that

$$
E U_{B}(q) \geq E U_{B}\left(\frac{1}{2}\right)
$$

Note that $\frac{\partial E U_{B}(q)}{\partial R}>0$ and $\frac{\partial E U_{B}\left(\frac{1}{2}\right)}{\partial R}<.0$. Therefore, there exists a $\hat{R}$ such that if $R \geq \hat{R}$, $E U_{B}(q) \geq E U_{B}\left(\frac{1}{2}\right)$. Further, note that $E U_{B}\left(q \mid R=q^{2}\right)>E U_{B}\left(\frac{1}{2} \mid R=q^{2}\right)$. Therefore $\hat{R}<q^{2}$. 
Define a loyal equilibrium as one where a bad bureaucrat implements the populist policy in the first period when a populist is in power.

Proof of Proposition 1. We conjecture that there exists an equilibrium with the following properties:

\section{Second Period}

- Behavior is as described in Lemmas 1.

- At the beginning of the period, populist politicians fire bureaucrats known to be good and non-populists politicians fire bureaucrats known to be bad, but both types retain bureaucrats who pooled in the first period.

\section{First Period}

- If $P_{p}^{1}$, bad bureaucrats implement $x^{1}=q$.

- If $P_{n}^{1}$, bad bureaucrats implement $x^{1}=\frac{1}{2}$.

- If $P_{p}^{1}$, good bureaucrats implement $x^{1}=q$ if $\omega^{1} \in\left[\underline{\omega^{1}}, \overline{\omega^{1}}\right]$ and $x^{1}=\omega^{1}$ otherwise.

- If $P_{n}^{1}$, good bureaucrats implement $x^{1}=\omega^{1}$.

- Populists retain bureaucrats if they implement $x^{1}=q$ and fire all others.

- Non-populists retain bureaucrats if they implement $x^{1}=\omega^{1}$ and fire all others.

First we recall the off-path beliefs for the second period politicians. Let populist politicians believe that if $x^{1} \neq q$ nor $\frac{1}{2}$ then the bureaucrat is good with probability 1 . Let non-populist politicians believe that if $x^{1} \neq \omega^{1}$, then the bureaucrat is bad with probability 1 . These off-path beliefs imply that if a bureaucrat implements a non-equilibrium policy she will be fired with certainty.

From Lemma 3, if $R \geq \hat{R}$, a loyal bureaucrat will implement $x^{1}=q$ if the first period politician is a populist. From Lemma 2, an expert will choose $x^{1}=q$ if $\omega^{1} \in\left[\underline{\omega^{1}}, \overline{\omega^{1}}\right]$ and $x^{1}=\omega^{1}$ otherwise if the first period politician is a populist.

If the first period politician is a non-populist, then bureaucrats act exactly as they do in the second period under a non-populist. 
From Lemma A.1, we know a populist wants to retain bad types and fire good types. When a populist politician observes $x^{1}=q$ and $\omega^{1}$, he knows that the bureaucrat is either bad for sure or his posterior matches his prior and he retains the bureaucrat. If he observes any other policy, he believes the bureaucrat is good and fires him.

It is clear a non-populist wants to retain good types and fire bad types. When a non-populist politician observes $x^{1}=\omega^{1}$, he knows that the bureaucrat is good and retains him. If he observes any other policy, he believes the bureaucrat is bad and fires him.

For the rest of the proofs, we assume $q+\sqrt{R} \geq 1$ (this is always true for $q \in\left[\frac{3}{4}, 1\right]$ when $R \geq \bar{R}$ ). This has no substantive implication (all results hold for $q \in\left[\frac{1}{2}, \frac{3}{4}\right.$ ) when $q+\sqrt{R}<1$ ), but it makes the comparative statics more straightforward.

Lemma A.3. If $q+\sqrt{R} \geq 1$, then $q+C \geq 1$.

Proof of Lemma A.3. From Lemma 2, If $q+\sqrt{R} \geq 1$, then

$$
q+C=q+\sqrt{\frac{1}{12}\left((1-\gamma) \pi\left(4 q^{3}-4 R^{3 / 2}-1\right)+(1-\gamma)+12 R(\pi(\sqrt{R}-q)+2)\right)} \text {. Therefore }
$$

we need

$$
R \leq \frac{1}{12}\left((1-\gamma) \pi\left(4 q^{3}-4 R^{3 / 2}-1\right)+(1-\gamma)+12 R(\pi(\sqrt{R}-q)+2)\right)
$$

which is always true.

Proof of Proposition 2. Because $\omega$ is distributed uniformly on the unit interval, the probability $\omega^{1}$ is greater than $q-C$ is $1-(q-C)$. Given a good bureaucrat and a populist politician in the first period, the probability the bureaucrat will feign loyalty is also $\operatorname{Pr}(F)=1-(q-C)=$ $1-\left(q-\sqrt{\frac{1}{12}\left((1-\gamma) \pi\left(4 q^{3}-4 R^{3 / 2}-1\right)+(1-\gamma)+12 R(\pi(\sqrt{R}-q)+2)\right)}\right)$.

We take the partial derivative of $\operatorname{Pr}(F)$ with respect to all parameters. Note that as $\underline{\omega}^{1}$ decreases, there is a wider range of $\omega^{1}$ such that the bureaucrat feigns loyalty. 


$$
\begin{aligned}
& \frac{\partial \operatorname{Pr}(F)}{\partial \gamma}=\frac{\pi\left(4 q^{3}-4 R^{3 / 2}-1\right)+1}{4 \sqrt{3(1-\gamma)\left(\pi\left(4 q^{3}-1\right)+1\right)-12((1-\gamma)-3) \pi R^{3 / 2}-36 R(\pi q-2)}}<0 \\
& \frac{\partial \operatorname{Pr}(F)}{\partial \pi}=\frac{(1-\gamma)\left(4 q^{3}-1\right)-4((1-\gamma)-3) R^{3 / 2}-12 q R}{4 \sqrt{3(1-\gamma)\left(\pi\left(4 q^{3}-1\right)+1\right)-12((1-\gamma)-3) \pi R^{3 / 2}-36 R(\pi q-2)}}>0
\end{aligned}
$$

if $\gamma \leq 1-\frac{12\left(R^{3 / 2}-q R\right)}{-4 q^{3}+4 R^{3 / 2}+1}$ and $q \geq \frac{1}{2^{2 / 3}}$ and negative otherwise.

$$
\begin{gathered}
\frac{\partial \operatorname{Pr}(F)}{\partial R}=\frac{\sqrt{3}(-((1-\gamma)-3) \pi \sqrt{R}-2 \pi q+4)}{2 \sqrt{(1-\gamma) \pi\left(4 q^{3}-1\right)-4((1-\gamma)-3) \pi R^{3 / 2}+(1-\gamma)-12 R(\pi q-2)}}>0 \\
\frac{\partial \operatorname{Pr}(F)}{\partial q}=\frac{\sqrt{3} \pi\left((1-\gamma) q^{2}-R\right)}{\sqrt{(1-\gamma) \pi\left(4 q^{3}-1\right)-4((1-\gamma)-3) \pi R^{3 / 2}+(1-\gamma)-12 R(\pi q-2)}}-1<0
\end{gathered}
$$

as required.

Proof of Lemma 4. First, note that turnover only happens when a good type acts sincerely. The probability of a sincere equilibrium with a populist in power in the first period is $\gamma$ times 1 minus the probability of feigning loyalty, or $q-\sqrt{\frac{1}{12}\left((1-\gamma) \pi\left(4 q^{3}-4 R^{3 / 2}-1\right)+(1-\gamma)+12 R(\pi(\sqrt{R}-q)+2)\right)}$ and the probability of sincere behavior with a non-populist in power in the first period is 1 (from Proposition 2).

Given sincere behavior, turnover can occur when there is a good bureaucrat paired with a populist and a bad one paired with a non-populist:

$$
\begin{aligned}
& \pi \cdot \gamma \cdot\left(q-\sqrt{\frac{1}{12}\left((1-\gamma) \pi\left(4 q^{3}-4 R^{3 / 2}-1\right)+(1-\gamma)+12 R(\pi(\sqrt{R}-q)+2)\right)}\right) \\
& +(1-\pi) \cdot(1-\gamma)
\end{aligned}
$$




$$
\begin{aligned}
& \text { Let } \tau_{p}:=\gamma \cdot\left(q-\sqrt{\frac{1}{12}\left((1-\gamma) \pi\left(4 q^{3}-4 R^{3 / 2}-1\right)+(1-\gamma)+12 R(\pi(\sqrt{R}-q)+2)\right)}\right) \text { and } \\
& \tau_{n}:=(1-\gamma) .
\end{aligned}
$$

Proof of Proposition 3. We take the partial derivatives with respect to all parameters.

$$
\begin{aligned}
& \frac{\partial \tau_{p}}{\partial \gamma}=\frac{\sqrt{(1-\gamma) \pi\left(4 q^{3}-4 R^{3 / 2}-1\right)+(1-\gamma)+12 R(\pi(\sqrt{R}-q)+2)}}{2 \sqrt{3}} \\
&-\frac{\gamma\left(\pi\left(4 q^{3}-4 R^{3 / 2}-1\right)+1\right)}{4 \sqrt{3} \sqrt{(1-\gamma) \pi\left(4 q^{3}-4 R^{3 / 2}-1\right)+(1-\gamma)+12 R(\pi(\sqrt{R}-q)+2)}}-q<0 \\
& \frac{\partial \tau_{p}}{\partial \pi}=-\frac{\gamma\left((1-\gamma)\left(4 q^{3}-4 R^{3 / 2}-1\right)+12 R(\sqrt{R}-q)\right)}{4 \sqrt{3} \sqrt{(1-\gamma) \pi\left(4 q^{3}-4 R^{3 / 2}-1\right)+(1-\gamma)+12 R(\pi(\sqrt{R}-q)+2)}} \geq 0
\end{aligned}
$$

if $\gamma \geq \frac{12 R(q+\sqrt{R})}{4 q^{3}+4 R^{3 / 2}-1}$ and negative otherwise.

$$
\begin{gathered}
\frac{\partial \tau_{p}}{\partial q}=\gamma\left(1-\frac{12(1-\gamma) \pi q^{2}-12 p R}{4 \sqrt{3} \sqrt{(1-\gamma) \pi\left(4 q^{3}-4 R^{3 / 2}-1\right)+(1-\gamma)+12 R(\pi(\sqrt{R}-q)+2)}}\right)>0 \\
\frac{\partial \tau_{n}}{\partial \gamma}=-1 \\
\frac{\partial \tau_{n}}{\partial \pi}=0 \\
\frac{\partial \tau_{n}}{\partial q}=0
\end{gathered}
$$

as required. 
Proof. Note that second period behavior is the same as in Proposition 1, except that there is now a chance of receiving $R$ when choosing a policy that leads to firing. Therefore the bad type will implement the populist policy if

$$
\begin{aligned}
R-E\left[(q-\omega)^{2}\right] & \geq(1-\phi) R-E\left[\left(\frac{1}{2}-\omega\right)^{2}\right] \\
R & \geq \frac{\left(q-\frac{1}{2}\right)^{2}}{\phi}
\end{aligned}
$$

Similarly, the good type will implement the populist policy if

$$
\begin{aligned}
R-\left(q-\omega^{2}\right)^{2} & \geq(1-\phi) R \\
\omega^{2} & \in[\max \{q-\sqrt{\phi R}, 0\}, \min \{q+\sqrt{\phi R}, 1\}]
\end{aligned}
$$

Similar to the baseline case, we will restrict attention to the case where $R \geq \frac{\left(q-\frac{1}{2}\right)^{2}}{\phi}$ and $q+\sqrt{(1-\phi) R} \geq 1$

Proof of Proposition 4. First period behavior is also the same under populist, except that it is less costly to act sincerely. Therefore we omit the details of the proof as it proceeds exactly as in Proposition 1, with the modification that the good bureaucrat will be fired with probability $(1-\phi)$ when she acts sincerely in the first period. The cutoff to feign loyalty for an expert under a populist is now

$$
\omega^{1} \geq q-\sqrt{\begin{array}{r}
\frac{1}{12} \phi\left(\gamma(\pi(4 q(-2 q+\sqrt{R \phi}+1)+4 R \phi-4 \sqrt{R \phi}+1)-1)+3 \pi(1-2 q)^{2}+1\right) \\
-\frac{1}{3}(\phi-1)\left(-p\left(-3 q R \phi+(q-1)^{3}+2(r \phi)^{3 / 2}\right)-6 R\right)+\frac{1}{3}\left(q^{3}-3 q^{2}+q(3-3 R \phi)+2(R \phi)^{3 / 2}+3 R-1\right)+R
\end{array}}
$$

Let there be a non-populist and a good bureaucrat in office in the first period. Then if the expert feigns being bad by implementing $\frac{1}{2}$ she will be fired by the non-populist with probability $\phi$. The expected utility for implementing the bad policy is 


\section{Expected Utility from the bad policy}

$$
\begin{aligned}
&-\left(\frac{1}{2}-\omega^{1}\right)^{2}+\phi\left(\pi \left(\frac{1}{3}(1-\gamma)\left(-3 q^{2}+3 q-1\right)\right.\right. \\
&\left.\left.+\frac{1}{3} \gamma\left(q^{3}-3 q^{2}+3 q-(R \phi)^{3 / 2}-1\right)\right)+(1-\pi)\left(\gamma 0-(1-\gamma) \frac{1}{12}\right)\right) \\
&+(1-\phi)\left(\frac{1}{3} \pi\left(q^{3}-3 q^{2}+q(3-3 R \phi)+2(R \phi)^{3 / 2}+3 R-1\right)+(1-\pi) R+R\right) \\
&=-\left(\frac{1}{2}-\omega\right)^{2}+\frac{1}{12}\left(\pi\left(4 q^{3}((\gamma-1) \phi+1)-4(\gamma+2) \phi(R \phi)^{3 / 2}+\phi(-\gamma+8 R \sqrt{R \phi}+1)-12 q^{2}+12 q(R(\phi-1) \phi+1)-4\right)+(\gamma-1) \phi-24 R(\phi-1)\right)
\end{aligned}
$$

Expected Utility from the sincere policy If she acts sincerely, a second period populist will attempt to fire her, and that will also succeed with probability $\phi$. However, she will be retained in period 1.

$$
\begin{aligned}
& R+\pi\left(\frac{1}{3}(1-\gamma)\left(-3 q^{2}+3 q-1\right) \phi\right. \\
& \left.+\frac{1}{3} \gamma\left(q^{3}-3 q^{2}+3 q-(R \phi)^{3 / 2}-1\right)+\frac{1}{3}(1-\phi)\left(q^{3}-3 q^{2}+q(3-3 R \phi)+2(R \phi)^{3 / 2}+3 R-1\right)\right)+(1-\pi) R \\
& =\frac{1}{3} \pi\left((\gamma-1)\left(3 q^{2}-3 q+1\right) \phi+\gamma\left(q^{3}-3 q^{2}+3 q-(R \phi)^{3 / 2}-1\right)\right. \\
& \left.+(1-\phi)\left(q^{3}-3 q^{2}+q(3-3 R \phi)+2(R \phi)^{3 / 2}+3 R-1\right)\right)-\pi R+2 R
\end{aligned}
$$

Feigning Loyalty The expert bureaucrat chooses the bad policy if

$$
\begin{aligned}
& -\left(\frac{1}{2}-\omega\right)^{2}+\frac{1}{12}\left(\pi \left(4 q^{3}((\gamma-1) \phi+1)-4(\gamma+2) \phi(R \phi)^{3 / 2}+\phi(-\gamma+8 R \sqrt{R \phi}+1)\right.\right. \\
& \left.\left.-12 q^{2}+12 q(R(\phi-1) \phi+1)-4\right)+(\gamma-1) \phi-24 R(\phi-1)\right) \\
& \geq \frac{1}{3} \pi\left((\gamma-1)\left(3 q^{2}-3 q+1\right) \phi+\gamma\left(q^{3}-3 q^{2}+3 q-(R \phi)^{3 / 2}-1\right)\right. \\
& \left.+(1-\phi)\left(q^{3}-3 q^{2}+q(3-3 R \phi)+2(R \phi)^{3 / 2}+3 R-1\right)\right)-\pi R+2 R
\end{aligned}
$$

Or 


$$
\omega^{1} \in\left[\frac{1}{2} \pm \sqrt{\left(\frac{1}{12}\left(\gamma\left(\pi\left(4(\phi-1)\left(q((q-3) q+3)-(R \phi)^{3 / 2}\right)-5 \phi+4\right)+\phi\right)+\phi(12(\pi-2) R+\pi-1)\right)\right)}\right]
$$

This interval is not guaranteed to exist. For some parameter values, the good type will never feign loyalty under a non-populist. When it does exist, it characterizes the interval of states of the world where the good type is willing to act as a loyalist even under a non-populist.

Proof of Proposition 6. $\underline{\omega}^{1 \alpha}$ is the same as in the baseline model, except we substitute $\frac{R}{\alpha}$ for all $R$. Then we have that $C_{\alpha} \leq C \forall \alpha \geq 1$, and therefore $\underline{\omega}^{1 \alpha} \geq \underline{\omega}^{1}$.

Proof. Note that the second period does not affect first period decisions under a non-populist. Therefore behavior will be the same under a non-populist as in the baseline case.

Now, let there be a first period populist and a good bureaucrat. A second period non-populist can rehire the first period bureaucrat, and will do so if the bureaucrat is known to be good. Therefore first period good bureaucrat will for sure be in office under a second period non-populist.

The good bureaucrat will feign loyalty if

$$
\begin{gathered}
R-\left(q-\omega^{1}\right)^{2}+\pi \frac{1}{3}\left(-3(q-1) R+(q-1)^{3}+2 R^{3 / 2}\right)+(1-\pi) R \\
\geq-\pi(1-\gamma) \cdot\left(\frac{1}{3}-q+q^{2}\right)-\pi \cdot \gamma \cdot \frac{1}{3}\left(R^{3 / 2}+(1-q)^{3}\right)-(1-\pi) R \\
\omega^{1} \geq q-\sqrt{\frac{1}{3} \pi\left((1-\gamma) q^{3}-3 q R+(\gamma+2) R^{3 / 2}+3 R\right)+R}
\end{gathered}
$$

